\title{
Imaging Predictors for Nonsentinel Lymph Node Metastases in Breast Cancer Patients
}

\author{
Yizi Cong ${ }^{\mathrm{a}}$ Suxia Wang ${ }^{\mathrm{b}}$ Haidong Zou $^{\mathrm{a}}$ Shiguang Zhu ${ }^{\mathrm{a}}$ Xingmiao Wang ${ }^{\text {a }}$ \\ Jianqiao Cao ${ }^{a}$ Ji Wang $^{\mathrm{a}}$ Yanqing Liu $^{\mathrm{a}}$ Guangdong Qiao ${ }^{\mathrm{a}}$ \\ ${ }^{a}$ Department of Breast Surgery, The Affiliated Yantai Yuhuangding Hospital of Qingdao University, Yantai, China; \\ ${ }^{b}$ Department of Pathology, The Affiliated Yantai Yuhuangding Hospital of Qingdao University, Yantai, China
}

\section{Keywords}

Breast neoplasms · Sentinel lymph node biopsy ·

Mammography · Ultrasonography · Predictive value of tests

\begin{abstract}
Background: The relationship between imaging features and nonsentinel lymph node (NSLN) metastasis is not clear. Objectives: To determine whether imaging features could predict NSLN metastasis in sentinel lymph node (SLN)-positive breast cancer patients and to provide new clues for avoiding unnecessary axillary lymph node dissection. Method: 171 patients with clinically negative axillary lymph nodes and a pathologically positive SLN were recruited between January 2007 and January 2014. According to the Breast Imaging Reporting and Data System (BI-RADS), the effects of clinicopathological factors, especially imaging features, on NSLN metastases were assessed by univariate and multivariate statistical analyses. Results: The average number of dissected SLNs was 2.11 (range, 1-6); 56 of the 171 (32.75\%) patients exhibited NSLN metastases. In univariate analysis, tumor size, number of positive SLNs, ratio of positive SLNs, mammographic mass margins, ultrasonographic mass margins, and ultrasonographic vascularity were significantly correlated with NSLN involvement. Furthermore, through multivariate analysis, tumor size, number of posi-
\end{abstract}


sentinel lymph node (NSLN) involvement after ALND, indicating that these patients received unnecessary ALND [2]. Thus, it is quite important to identify patients with SLN involvement only but without NSLN metastases.

Over the past few years, multiple studies have been conducted to identify the clinicopathological factors that could predict NSLN metastases, including the method of detection (hematoxylin and eosin, HE), SLN metastases $>2 \mathrm{~mm}$ in size, extracapsular extension in the SLN, $>1$ positive SLN, ratio of positive sentinel nodes $>50 \%$, tumor size $>2 \mathrm{~cm}$, and lymphovascular invasion in the primary tumor $[2,3]$. Furthermore, some mathematical models have been developed to predict the NSLN status [4-6]. However, the predicted probability of these models was not very high. Therefore, new factors are needed to help improve the predicted probability.

Mammography and ultrasonography images could reflect alterations in breast anatomy and pathology. Previous studies showed that mammographic tumor features were associated with axillary lymph node metastases in breast cancer patients [7-10], and studies also revealed mammographic spiculation as a positive prognostic marker due to the correlation with low-grade tumors and improved survival [11-13]. Besides, vessels in tumors which could be detected by color Doppler ultrasound were also correlated with lymph node metastases. Based on the above theory, we supposed that mammographic and ultrasonographic tumor features could also predict NSLN metastases.

In this study, we investigated the imaging features that could predict NSLN metastases in breast cancer patients with clinically negative axillary lymph nodes. Through this study, we expected to provide more information for the prediction of NSLN metastases.

\section{Materials and Methods}

\section{Patient History}

This was a retrospective review study including 537 breast cancer patients with clinically negative axillary lymph nodes who received SLNB from January 2007 through January 2014. Patients treated with neoadjuvant chemotherapy were excluded. No enlarged lymph nodes were palpable, and absence of any suspicious findings on ultrasound was considered axillary negative [14]. Of these patients with clinically negative axillary lymph nodes, 171 patients with a pathologically positive SLN received ALND. The medical records of these 171 patients were retrieved from our registry, and their clinicopathological characteristics were analyzed. All images for this study were reviewed by 2 breast radiologists in our hospital. The mammographic and ultrasonographic features of the tumors in the current study were evaluated according to BI-RADS criteria [15].

Sentinel Lymph Node Biopsy

SLN mapping was performed using lymphoscintigraphy with methylene blue dye. On the day of operation, technetium-99 sulfur colloid (Beijing Shihong Pharmaceutical Development Center, Beijing, China) was injected intradermally above the tumor, peritumorally, at the areola of the breast, or at the surgical site of the previous biopsy. Scans of the involved breast and axilla were acquired $2 \mathrm{~h}$ after tracer injection. Methylene blue dye (Jumpcan, Taixing, China) was injected 15 min before surgery. During surgery, the SLN was localized by using a $\gamma$-probe (Neoprobe Corporation, Dublin, OH, USA). The SLN was defined as a blue lymph node and/or a lymph node with an ex vivo radioactive count $\geq 10 \%$ of the ex vivo radioactive count of the hottest lymph node. In addition, any clinically suspicious, palpable lymph nodes were also removed.

\section{Pathological Examinations}

All SLNs were subjected to standard frozen section evaluation with HE-stained section. The first SLN defined as the bluest or hottest lymph node was bisected longitudinally and frozen; other SLNs were frozen intactly. Frozen sections were taken with a microtome setting of $4 \mu \mathrm{m}$. The remaining nodal tissue was fixed in $10 \%$ formalin and embedded in paraffin. After this fixation, serial sections of the SLN were obtained for definitive analysis. The HER2 overexpression status was determined according to the American Society of Clinical Oncology guidelines [16]. According to different combinations of ER, PR, HER2 status, and Ki67, patients were categorized into 4 subgroups as follows: luminal A, luminal B, HER2 overexpression, and triple negative [17].

\section{Statistical Analyses}

Statistical analyses were performed using SPSS 19.0 (IBM Corporation, New York, NY, USA). A $\chi^{2}$ test, Fisher's exact test, and analysis of variance were used to compare patients and tumor characteristics. Multivariable analyses were performed on variables with $p<0.050$ from the univariable analyses by logistic regression. Independent sample $t$ tests were used to compare the factors which influenced the number of NSLN metastases. A $p$ value of 0.050 or smaller was considered statistically significant.

\section{Results}

\section{Baseline Characteristics of the Patients}

A total of 171 patients with invasive breast cancer had a positive SLN, and all received ALND. The average number of total metastatic lymph nodes was 1.95 (range, 1-11). The median age of these patients was 49 years (range, 24-75 years). The average number of SLNs dissected was 2.11 (range, 1-6). Of these 171 patients, 56 patients $(32.75 \%)$ had at least 1 positive NSLN. In patients with 1,2, or more SLN metastases, the average numbers of NSLN metastases were $0.59 \pm 1.258$ and $1.18 \pm 1.749(p=0.027)$. The proportion of patients who had the luminal A subtype was $42.69 \%$, and the proportion of patients with luminal B, HER2 overexpression, and triple-negative subtypes was $37.43,6.43$, and $6.43 \%$, respectively. The subtypes of another $7.02 \%$ patients were unclear because of HER2++ on immunohistochemistry without fluorescence in situ hybridization test. Baseline characteristics of these 171 breast cancer patients are shown in Table 1. 
Of these 171 patients, 8 patients received tumor resection biopsy in other hospitals, so imaging data were not available. Tables 2 and 3 list the distribution of mammographic and ultrasonographic appearances among 163 patients with available information, and they also show the correlations between these appearances and lymph node status.

\section{Factors Predictive of NSLN Involvement}

In the univariate analysis of NSLN metastases (Tables 1-3), larger tumors were more common in the NSLN-positive group than the NSLN-negative group $(p=0.022)$. The number of positive SLNs in the NSLNpositive group was higher than in the NSLN-negative group $(p=0.000)$. However, age at diagnosis $(p=0.639)$, histological grade $(p=0.134)$, SLN number examined $(p=0.935)$, and molecular subtypes $(p=0.425)$ did not show significant differences between these 2 groups. $\mathrm{Pa}$ tients with the luminal A subtype seemed to have a higher risk of NSLN metastases than other subtypes, but there was no statistically significant difference.

On mammography, circumscribed, microlobulated, obscure, and indistinct features were grouped together to provide adequate numbers for comparison with spiculated numbers. We found that masses with spiculated margins were more commonly observed in the NSLNpositive group compared with the NSLN-negative group $(p=0.030)$; breast density, mass shape, calcifications, and associated features did not reveal statistical differences between these 2 groups (Table 2).

Ultrasonographically, proportions of microlobulated and circumscribed margins were merged to compare them with proportions of indistinct, angular, or spiculated margins. Similarly, masses with indistinct, angular, or spiculated margins were more commonly found in the NSLN-positive group $(p=0.029)$. Besides this, Doppler color imaging revealed that masses with internal, rim, or internal plus rim vascularity were more commonly found in the NSLN-positive group, and absence of vascularity occurred more often in the NSLN-negative group ( $p=$ 0.040) (Table 3).

In multivariate analysis, tumor size $(p=0.027)$, number of positive SLNs ( $p=0.003$ ), mammographic mass margins $(p=0.038)$, and ultrasonographic vascularity $(p=0.036)$ were all significant predictive factors of NSLN metastasis, while the ratio of positive SLN and ultrasonographic mass margins showed no statistical differences (Table 4).

At last, we analyzed which factors could predict the tumor burden in NSLN. Table 5 indicates that ultrasonographic vascularity $(p=0.032)$ can also predict the tumor burden in NSLN besides the number of positive SLNs $(p=0.027)$. Tumor size $(p=0.107)$ and mammographic mass margins $(p=0.390)$ also tend to predict the NSLN burden, but there was no statistical significance.
Table 1. Characteristics of the breast cancer patients with positive SLNs and univariate analysis of NSLN metastases

\begin{tabular}{|c|c|c|c|c|}
\hline Variable & $\begin{array}{l}\text { Total } \\
(n=171)\end{array}$ & $\begin{array}{l}\text { Negative } \\
\text { NSLN } \\
(n=115)\end{array}$ & $\begin{array}{l}\text { Positive } \\
\text { NSLN } \\
(n=56)\end{array}$ & $p$ \\
\hline Age & & & & 0.639 \\
\hline$\leq 50$ years & 99 & 68 & 31 & \\
\hline$>50$ years & 72 & 47 & 25 & \\
\hline Tumor size & & & & 0.022 \\
\hline $\mathrm{T} 1$ & 112 & 81 & 30 & \\
\hline $\mathrm{T} 2$ & 55 & 31 & 25 & \\
\hline NA & 4 & 3 & 1 & \\
\hline Histological grade & & & & 0.134 \\
\hline I & 37 & 29 & 8 & \\
\hline II & 108 & 71 & 37 & \\
\hline III & 24 & 13 & 11 & \\
\hline NA & 2 & 2 & 0 & \\
\hline SLNs & & & & 0.935 \\
\hline 1 & 53 & 37 & 16 & \\
\hline 2 & 70 & 46 & 24 & \\
\hline 3 & 31 & 20 & 11 & \\
\hline$\geq 4$ & 17 & 12 & 5 & \\
\hline Positive SLNs & & & & 0.000 \\
\hline 1 & 137 & 101 & 36 & \\
\hline$\geq 2$ & 34 & 14 & 20 & \\
\hline Ratio of positive SLN & & & & 0.034 \\
\hline$\leq 50 \%$ & 87 & 65 & 22 & \\
\hline$>50 \%$ & 84 & 50 & 34 & \\
\hline Molecular subtype & & & & 0.425 \\
\hline Luminal A & 73 & 44 & 29 & \\
\hline Luminal B & 64 & 45 & 19 & \\
\hline HER2 overexpression & 11 & 9 & 2 & \\
\hline Triple negative & 11 & 8 & 3 & \\
\hline NA & 12 & 9 & 3 & \\
\hline
\end{tabular}

NA, not available; SLN, sentinel lymph node; HER2, human epidermal growth factor receptor 2; NSLN, non-SLN.

\section{Discussion}

SLNB is widely used to assess axillary status in patients with early-stage invasive breast cancer. Generally, ALND is the standard treatment for most patients with a positive SLN. However, the therapeutic efficacy of this procedure is controversial because $40-60 \%$ of patients lack NSLN involvement after ALND [2]. In order to avoid unnecessary ALND, many authors have tried to predict in which patients ALND can be safely omitted, and various risk factors for probable NSLN metastases have been identified [3]. In addition, some nomograms have been developed to predict NSLN status $[5,18]$. However, the predictive value of these models does not reach the intended high accuracy level. Therefore, new factors and methods are needed to improve the predicted probability.

In this study, we found additional nodal involvement in only $32.75 \%$ of patients, which is lower than the reported range of $40-60 \%$ [2]. The variation in NSLN in- 
Table 2. Mammography findings of breast cancer patients with positive SLNs and univariate analysis of NSLN metastases

\begin{tabular}{|c|c|c|c|c|}
\hline Mammography findings & $\begin{array}{l}\text { Total } \\
(n=163)\end{array}$ & $\begin{array}{l}\text { Negative NSLN } \\
(n=108)\end{array}$ & $\begin{array}{l}\text { Positive NSLN } \\
(n=55)\end{array}$ & $p$ \\
\hline \multicolumn{5}{|l|}{ Breast density } \\
\hline 1 & 27 & 17 & 10 & \multirow[t]{4}{*}{0.527} \\
\hline 2 & 37 & 28 & 9 & \\
\hline 3 & 64 & 42 & 22 & \\
\hline 4 & 35 & 21 & 14 & \\
\hline \multicolumn{5}{|l|}{ Result } \\
\hline Normal (BI-RADS 1 or 2 ) & 12 & 11 & 1 & \multirow[t]{2}{*}{0.061} \\
\hline Abnormal & 151 & 97 & 54 & \\
\hline \multicolumn{5}{|l|}{ Lesion type } \\
\hline Mass & 89 & 61 & 28 & \multirow[t]{4}{*}{0.192} \\
\hline Mass with calcifications & 49 & 30 & 19 & \\
\hline Calcification only & 11 & 6 & 5 & \\
\hline Other imaging & 2 & 0 & 2 & \\
\hline \multicolumn{5}{|l|}{ Mass shape } \\
\hline Oval & 15 & 7 & 8 & \multirow[t]{2}{*}{0.095} \\
\hline Irregular & 123 & 84 & 39 & \\
\hline \multicolumn{5}{|l|}{ Mass margins } \\
\hline Circumscribed & 7 & 6 & 1 & \multirow{5}{*}{$0.030^{\mathrm{a}}$} \\
\hline Microlobulated & 8 & 6 & 2 & \\
\hline Obscure & 6 & 3 & 3 & \\
\hline Spiculated & 45 & 24 & 21 & \\
\hline Indistinct & 72 & 52 & 20 & \\
\hline \multicolumn{5}{|l|}{ Calcifications } \\
\hline No & 104 & 73 & 31 & \multirow[t]{6}{*}{$0.125^{\mathrm{b}}$} \\
\hline Typically benign & 1 & 1 & 0 & \\
\hline Amorphous & 5 & 3 & 2 & \\
\hline Coarse heterogeneous & 6 & 3 & 3 & \\
\hline Fine pleomorphic & 43 & 25 & 18 & \\
\hline Fine linear or branching & 4 & 3 & 1 & \\
\hline \multicolumn{5}{|l|}{ Associated features } \\
\hline \multicolumn{5}{|l|}{ Skin retraction } \\
\hline Yes & 5 & 3 & 2 & \multirow[t]{2}{*}{1.000} \\
\hline No & 158 & 105 & 53 & \\
\hline \multicolumn{5}{|l|}{ Nipple retraction } \\
\hline Yes & 12 & 7 & 5 & \multirow[t]{2}{*}{0.541} \\
\hline No & 151 & 101 & 50 & \\
\hline \multicolumn{5}{|l|}{ Skin thickening } \\
\hline Yes & 13 & 7 & 6 & \multirow[t]{2}{*}{0.366} \\
\hline No & 150 & 101 & 49 & \\
\hline Mass size, $\mathrm{cm}$ & & $2.056 \pm 0.707$ & $2.355 \pm 0.773$ & 0.024 \\
\hline
\end{tabular}

${ }^{a}$ Circumscribed, microlobulated, obscure, and indistinct numbers were grouped together to provide adequate numbers for comparison with spiculated numbers. ${ }^{b}$ No calcification and typically benign numbers were grouped together to provide adequate numbers for comparison with other types of calcifications.

volvement can partly be explained by differences in the size of study populations and rigorous use of preoperative axillary ultrasound. Another reason may be that patients with suspicious lymph nodes on ultrasound who received core needle biopsy were excluded in our study.

Similar to previous research, we also revealed that primary tumor size and the number of positive SLNs were predictors of NSLN metastases. Patients with a tumor size $>2 \mathrm{~cm}$ had a significantly higher risk of NSLN metastases.
Besides, the NSLN metastasis risk also increased with increasing number of positive SLNs. However, the ratio of positive SLNs and histological grade did not reach significant predictive values. A previous study found significant differences in different subtypes in terms of NSLN metastases [19]. Zhou et al. [20] reported that patients with luminal A and B subtypes had a higher risk of NSLN metastases than those with triple-negative breast cancer. However, in a study by Gülben et al. [21], luminal A subtype of breast 
Table 3. Ultrasonographic findings of breast cancer patients with positive SLNs and univariate analysis of NSLN metastases

\begin{tabular}{|c|c|c|c|c|}
\hline Ultrasound findings & $\begin{array}{l}\text { Total } \\
(n=163)\end{array}$ & $\begin{array}{l}\text { Negative NSLN } \\
(n=108)\end{array}$ & $\begin{array}{l}\text { Positive NSLN } \\
(n=55)\end{array}$ & $p$ \\
\hline \multicolumn{5}{|l|}{ Mass shape } \\
\hline Round & 1 & 1 & 0 & \multirow[t]{3}{*}{$0.664^{\mathrm{a}}$} \\
\hline Oval & 4 & 3 & 1 & \\
\hline Irregular & 158 & 104 & 54 & \\
\hline \multicolumn{5}{|l|}{ Mass margins } \\
\hline Circumscribed & 10 & 8 & 2 & \multirow[t]{5}{*}{$0.029^{\mathrm{b}}$} \\
\hline Indistinct & 56 & 40 & 16 & \\
\hline Microlobulated & 20 & 17 & 3 & \\
\hline Angular & 60 & 33 & 27 & \\
\hline Spiculated & 17 & 10 & 7 & \\
\hline \multicolumn{5}{|l|}{ Orientation } \\
\hline Parallel & 104 & 68 & 36 & \multirow[t]{2}{*}{0.754} \\
\hline Not parallel & 59 & 40 & 19 & \\
\hline \multicolumn{5}{|l|}{ Echo pattern } \\
\hline Hypoechoic & 2 & 2 & 0 & \\
\hline Hyperechoic & 1 & 1 & 0 & \multirow{3}{*}{$0.301^{\mathrm{c}}$} \\
\hline Heterogeneous & 159 & 104 & 55 & \\
\hline Complex cystic and solid & 1 & 1 & 0 & \\
\hline \multicolumn{5}{|l|}{ Posterior feature } \\
\hline No features & 119 & 80 & 39 & \multirow{4}{*}{$0.489^{\mathrm{d}}$} \\
\hline Shadowing & 42 & 26 & 16 & \\
\hline Enhancement & 1 & 1 & 0 & \\
\hline Combined pattern & 1 & 1 & 0 & \\
\hline \multicolumn{5}{|l|}{ Calcifications } \\
\hline No & 114 & 78 & 36 & \multirow[t]{2}{*}{0.373} \\
\hline In mass & 49 & 30 & 19 & \\
\hline \multicolumn{5}{|l|}{ Vascularity } \\
\hline Absent & 36 & 29 & 7 & \multirow[t]{4}{*}{$0.040^{\mathrm{e}}$} \\
\hline Internal & 91 & 55 & 36 & \\
\hline Rim & 22 & 16 & 6 & \\
\hline Internal + rim & 14 & 8 & 6 & \\
\hline Mass size, $\mathrm{cm}$ & & $1.934 \pm 0.661$ & $2.429 \pm 0.883$ & 0 \\
\hline
\end{tabular}

\footnotetext{
${ }^{a}$ Round and oval numbers were grouped together to provide adequate numbers for comparison with irregular numbers. ${ }^{b}$ Proportions of microlobulated and circumscribed margins compared with proportions of indistinct, angular, or spiculated margins. ${ }^{c}$ Hypoechoic, hyperechoic, and complex cystic and solid were grouped together to provide adequate numbers for comparison with heterogeneous. ${ }^{\mathrm{d}}$ Category enhancement, no features, and combined pattern were grouped together to allow adequate group size for comparison. ${ }^{\mathrm{e}}$ Internal, rim, and internal + rim were grouped together to provide adequate numbers for comparison.
}

cancer had the lowest risk of NSLN metastases, while patients with the luminal/HER2+ subtype had a higher risk of NSLN metastases than those with the luminal A subtype, and the HER2-overexpressing subtype was significantly associated with NSLN metastases. In our previous studies [19-21], molecular subtypes were divided based on ER, (and/or) PR, and HER2 status. Ki67 was also used to distinguish luminal A and B (HER2-negative) subtypes in our study which was different from the above research. Our results revealed patients with the luminal A subtype had a higher risk of NSLN metastases than those with other subtypes, but this difference was not statistically significant, which was in agreement with the study by Zhou et al. [20].
Tumor features on mammography were also related to axillary lymph node metastases in breast cancer patients. Regarding the nodal involvement, previous data demonstrated that pleomorphic calcifications [7, 10], overlying skin thickening, or dimpling on mammogram were more frequently present in the lymph node-positive group [7]. Recently, a study showed that higher probability of malignant calcifications was associated with more lymph node involvement compared with patients with spiculated masses, and a nonstellate mass had a lower risk of lymphatic metastases [8]. However, another study showed that tumors appearing as calcifications were more often ALN negative compared with tumors appearing as a distinct mass; 
Table 4. Multivariate analysis of factors affecting NSLN metastases

\begin{tabular}{|c|c|c|c|}
\hline Variable & OR & $95 \% \mathrm{CI}$ & $p$ \\
\hline \multicolumn{4}{|l|}{ Tumor size } \\
\hline $\mathrm{T} 1$ & 1 & Reference & \\
\hline $\mathrm{T} 2$ & 2.466 & $1.109-5.484$ & 0.027 \\
\hline \multicolumn{4}{|l|}{ Positive SLNs } \\
\hline 1 & 1 & Reference & \\
\hline$\geq 2$ & 4.737 & $1.712-13.107$ & 0.003 \\
\hline \multicolumn{4}{|l|}{ Mammographic mass margins } \\
\hline Circumscribed + microlobulated + obscure + indistinct & 1 & Reference & \\
\hline Spiculated & 2.37 & $1.049-5.353$ & 0.038 \\
\hline \multicolumn{4}{|l|}{ Ultrasonographic vascularity } \\
\hline Absent & 1 & Reference & \\
\hline Internal, rim, or internal + rim & 3.128 & $1.080-9.059$ & 0.036 \\
\hline \multicolumn{4}{|l|}{ Ratio of positive SLN } \\
\hline$\leq 50 \%$ & 1 & Reference & \\
\hline$>50 \%$ & 1.005 & $0.433-2.335$ & 0.99 \\
\hline \multicolumn{4}{|l|}{ Ultrasonographic mass margins } \\
\hline Circumscribed + microlobulated & 1 & Reference & \\
\hline Indistinct + angular + spiculated & 2.162 & $0.709-6.595$ & 0.175 \\
\hline
\end{tabular}

OR, odds ratio; CI, confidence interval.

Table 5. Analysis of factors affecting tumor burden in NSLN

\begin{tabular}{lrrr}
\hline Variable & Cases & Positive NSLN $(\mathrm{x} \pm \mathrm{s}), n$ & $p$ \\
\hline Tumor size & & & \\
$\quad$ T1 & 111 & $0.59 \pm 1.351$ & 0.107 \\
T2 & 56 & $0.96 \pm 1.464$ & \\
Positive SLNs & 137 & $0.59 \pm 1.258$ & 0.027 \\
$\quad 1$ & 34 & $1.18 \pm 1.749$ & \\
$\geq 2$ & & & 0.39 \\
Mammographic mass margins & 93 & $0.62 \pm 1.351$ & \\
$\quad$ Circumscribed + microlobulated + obscure + indistinct & 45 & $0.82 \pm 1.072$ & 0.032 \\
$\quad$ Spiculated & 36 & $0.39 \pm 0.934$ & \\
Ultrasonographic vascularity & 127 & $0.83 \pm 1.505$ & \\
$\quad$ Absent & & \\
$\quad$ Internal, rim, or internal + rim & & \\
\hline
\end{tabular}

tumors presenting as an ill-defined mass and spiculated appearance tended to be more often ALN positive than tumors which presented as a distinct mass [9]. In our present study, spiculated mammographic margins had a significantly higher risk of NSLN metastases, which was basically consistent with the above 2 studies. Besides, patients with malignant calcification also had a tendency to be more prone to lymph node metastases but without statistical significance. Why was there a relationship between spiculated mammographic margins and NSLN metastases? As previously reported, loss of adhesion factors on carcinoma cells was considered to play a role in the histological appearance of invasive carcinoma as loosely dispersed linear columns of cells and a typical discrete mass [22,23]. This more diffuse infiltrative pattern may explain some of the typical im- aging appearances of tumors, such as spiculation and distortion [22]. Thus, based on this theory, we considered that loss of adhesion factors may increase potential lymph node metastases in spiculated mammographic tumors. As to why mammographic spiculation may be a good prognostic marker, another study showed that the spiculation feature was associated with high ER and PR expression [24]. Therefore, we thought that due to the better treatment, especially endocrine therapy, spiculated mammographic tumors could still achieve a good prognosis, although lymphatic metastases are more likely to occur.

Regarding tumor blood supply, it is well established that microvessel formation in tumors is closely correlated with lymph node metastases. Several studies confirmed this theory by Doppler sonography [25-27]. Tumor vascularity 
revealed by power Doppler sonography was strongly correlated with the detection of lymph node involvement and lymphatic vascular invasion, with sensitivities of 93 and $90 \%$, respectively [25], especially for small tumors in predicting lymph node metastasis [26, 27]. In our study, ultrasonographic vascularity was an independent predictive factor of NSLN involvement and NSLN tumor burden, which was in agreement with previous studies.

In conclusion, our study indicated that tumor size, number of positive SLNs, mammographic mass margins, and ultrasonographic vascularity were independent predictors of NSLN metastases in SLN-positive breast cancer. Furthermore, the number of positive SLNs and ultrasonographic vascularity could also predict the tumor burden in NSLN. These results support the development of new nomograms including mammographic mass margins and ultrasonographic vascularity to increase predictive accuracy.

The limitations of this study include the small sample size and the retrospective design of the study. However, the conclusions of the present study are useful when planning additional studies. Future prospective studies in a larger patient cohort are needed to validate our findings.

\section{Acknowledgments}

The authors thank all staff members of the Departments of Imaging and Pathology who were involved in diagnosing our patients.

\section{Statement of Ethics}

The protocol was approved by the Hospital Human Ethical Committee (201521). Informed consent had been obtained from all patients before surgery and specimen sampling were conducted.

\section{Disclosure Statement}

The authors have no conflicts to disclose.

\section{Funding Sources}

The study was supported by the key project of research and development plan of Shandong Province (No. 2018GSF118125) and Yantai City (No. 2017YD007).

\section{References}

1 Giuliano AE, Hunt KK, Ballman KV, Beitsch PD, Whitworth PW, Blumencranz PW, et al. Axillary dissection vs no axillary dissection in women with invasive breast cancer and sentinel node metastasis: a randomized clinical trial. JAMA. 2011 Feb;305 (6):569-75.

2 van la Parra RF, Peer PG, Ernst MF, Bosscha K. Meta-analysis of predictive factors for nonsentinel lymph node metastases in breast cancer patients with a positive SLN. Eur J Surg Oncol. 2011 Apr;37(4):290-9.

3 Moghaddam Y, Falzon M, Fulford L, Williams NR, Keshtgar MR. Comparison of three mathematical models for predicting the risk of additional axillary nodal metastases after positive sentinel lymph node biopsy in early breast cancer. Br J Surg. 2010 Nov;97(11): 1646-52.

4 Canavese G, Bruzzi P, Catturich A, Vecchio C, Tomei D, Del Mastro L, et al. A risk score model predictive of the presence of additional disease in the axilla in early-breast cancer patients with one or two metastatic sentinel lymph nodes. Eur J Surg Oncol. 2014 Jul; 40(7):835-42.

5 Koca B, Kuru B, Ozen N, Yoruker S, Bek Y. A breast cancer nomogram for prediction of non-sentinel node metastasis - validation of fourteen existing models. Asian Pac J Cancer Prev. 2014;15(3):1481-8.

6 Kuo YL, Chen WC, Yao WJ, Cheng L, Hsu HP, Lai HW, et al. Validation of Memorial Sloan-Kettering Cancer Center nomogram for prediction of non-sentinel lymph node metastasis in sentinel lymph node positive breast cancer patients an international comparison. Int J Surg. 2013;11(7):538-43.
7 Kollias J, Gill PG, Beamond B, Rossi H, Langlois S, Vernon-Roberts E. Clinical and radiological predictors of complete excision in breast-conserving surgery for primary breast cancer. Aust N Z J Surg. 1998 Oct; 68(10):702-6.

8 Li JN, Xu J, Wang J, Qing C, Zhao YM, Liu PF. Correlation between mammograghic findings and clinical/ pathologic features in women with small invasive breast carcinomas. Asian Pac J Cancer Prev. 2014;15(24):10643-6.

9 Sartor H, Borgquist S, Hartman L, Olsson A, Jawdat F, Zackrisson S. Do mammographic tumor features in breast cancer relate to breast density and invasiveness, tumor size, and axillary lymph node involvement? Acta Radiol. 2015 May;56(5):536-44.

10 Sun SS, Zhang B, Zhao HM, Cao XC. Association between mammographic features and clinicopathological characteristics in invasive ductal carcinoma of breast cancer. Mol Clin Oncol. 2014 Jul;2(4):623-9.

11 Alexander MC, Yankaskas BC, Biesemier KW. Association of stellate mammographic pattern with survival in small invasive breast tumors. AJR Am J Roentgenol. 2006 Jul; 187(1):29-37.

12 Evans AJ, Pinder SE, James JJ, Ellis IO, Cornford E. Is mammographic spiculation an independent, good prognostic factor in screening-detected invasive breast cancer? AJR Am J Roentgenol. 2006 Nov;187(5):1377-80.

13 Tabar L, Tony Chen HH, Amy Yen MF, Tot T, Tung TH, Chen LS, et al. Mammographic tumor features can predict long-term outcomes reliably in women with 1-14-mm invasive breast carcinoma. Cancer. 2004 Oct; 101(8):1745-59.
14 Reynders A, Brouckaert O, Smeets A, Laenen A, Yoshihara E, Persyn F, et al. Prediction of non-sentinel lymph node involvement in breast cancer patients with a positive sentinel lymph node. Breast. 2014 Aug;23(4):453-9.

15 D’Orsi CJ, Sickles EA, Mendelson EB, Morris EA, et al. ACR BI-RADS ${ }^{\circledR}$ Atlas, Breast Imaging Reporting and Data System. Reston, VA: American College of Radiology; 2013.

16 Wolff AC, Hammond ME, Hicks DG, Dowsett M, McShane LM, Allison KH, et al.; American Society of Clinical Oncology; College of American Pathologists. Recommendations for human epidermal growth factor receptor 2 testing in breast cancer: American Society of Clinical Oncology/College of American Pathologists clinical practice guideline update. Arch Pathol Lab Med. 2014 Feb;138(2):241-56.

17 Goldhirsch A, Wood WC, Coates AS, Gelber RD, Thürlimann B, Senn HJ; Panel members. Strategies for subtypes-dealing with the diversity of breast cancer: highlights of the St. Gallen International Expert Consensus on the Primary Therapy of Early Breast Cancer 2011. Ann Oncol. 2011 Aug;22(8):1736-47.

18 Al-Masri M, Darwazeh G, El-Ghanem M, Hamdan B, Sughayer M. Assessment of an existing and modified model for predicting non sentinel lymph node metastasis in breast cancer patients with positive sentinel node biopsy. Gulf J Oncolog. 2013 Jan;1(13):15-22.

19 Reyal F, Belichard C, Rouzier R, de Gournay E, Senechal C, Bidard FC, et al. Non-sentinel lymph node metastasis prediction in breast cancer with metastatic sentinel lymph node: impact of molecular subtypes classification. PLoS One. 2012;7(10):e47390. 
20 Zhou W, He Z, Xue J, Wang M, Zha X, Ling $\mathrm{L}$, et al. Molecular subtype classification is a determinant of non-sentinel lymph node metastasis in breast cancer patients with positive sentinel lymph nodes. PLoS One. 2012;7(4): e35881.

21 Gülben K, Berberoğlu U, Aydoğan O, Kınaş $\mathrm{V}$. Subtype is a predictive factor of nonsentinel lymph node involvement in sentinel node-positive breast cancer patients. J Breast Cancer. 2014 Dec;17(4):370-5.
22 Doyle S, Evans AJ, Rakha EA, Green AR, Ellis IO. Influence of E-cadherin expression on the mammographic appearance of invasive nonlobular breast carcinoma detected at screening. Radiology. 2009 Oct;253(1):51-5.

23 Gastl G, Spizzo G, Obrist P, Dünser M, Mikuz G. Ep-CAM overexpression in breast cancer as a predictor of survival. Lancet. $2000 \mathrm{Dec}$; 356(9246):1981-2.

24 Moriuchi H, Yamaguchi J, Hayashi H, Ohtani $\mathrm{H}$, Shimokawa I, Abiru H, et al. Cancer Cell Interaction with Adipose Tissue: Correlation with the Finding of Spiculation at Mammography. Radiology. 2016 Apr;279(1):56-64.
25 Mehta TS, Raza S. Power Doppler sonography of breast cancer: does vascularity correlate with node status or lymphatic vascular invasion? AJR Am J Roentgenol. 1999 Aug; 173(2):303-7

26 Lee WJ, Chu JS, Huang CS, Chang MF, Chang KJ, Chen KM. Breast cancer vascularity: color Doppler sonography and histopathology study. Breast Cancer Res Treat. 1996;37(3) 291-8.

27 Okuyama N, Murakuni H, Ogata H. The use of Doppler ultrasound in evaluation of breast cancer metastasis to axillary lymph nodes. Oncol Rep. 2004 Feb;11(2):389-93. 